\title{
IFSUL GO: Design de aplicativo complementar ao novo sistema de sinalização do IFSUL - Câmpus Pelotas
}

\author{
IFSUL GO: Mobile Application Design \\ Complementary to the New IFSUL \\ - Campus Pelotas Signage System
}

Alexsandro Alcantara Borges ${ }^{[1]}$, Rafael Klumb Arnoni ${ }^{[2]}$

Resumo: O presente trabalho apresenta os resultados do Trabalho de Conclusão de Curso do Bacharelado em Design do IFSUL Câmpus Pelotas, o qual teve como objetivo a concepção de um aplicativo para smartphones complementar ao novo Sistema de Sinalização do IFSUL Câmpus Pelotas. Foram estudados conceitos de Design da Informação e Design de Experiência do Usuário a partir de uma pesquisa qualitativa de revisão bibliográfica. Após, foi realizada uma coleta de dados com a equipe do Projeto do Sistema de Sinalização e uma análise de amostra intencional de dois apps de Wayfinding de instituições de ensino. A metodologia projetual utilizada foi a de Design Thinking de Ambrose e Harris juntamente ao framework de Garrett, resultando em um protótipo do app denominado IFSUL GO.

Palavras-chave: Design de Interação. Experiência do Usuário. Design de Aplicativo. Wayfinding. Sinalização.

Abstract: This paper presents the results of the Undergraduate Thesis of the Bachelor of Design degree at IFSUL Câmpus Pelotas, and aimed to design an application for smartphones to complement the new Signage System at IFSUL Câmpus Pelotas. Concepts of Information Design and User Experience Design were studied from a qualitative research of bibliographic review. Afterwards, a data collection with the Signage

[1] Bacharel em Design, IFSUL. alex.alcantarab@gmail.com

[2] Mestre em Memória Social e Patrimônio

Cultural, UFPEL.rafaelarnoni@ifsul.edu.br 
Project team and an intentional sample analysis of two educational institutions' Wayfinding applications were carried out. The methodology aplied was Design Thinking by Ambrose and Harris together with Garrett's framework, resulting in a prototype of the app called IFSUL GO.

Keywords:Interaction Design; UserExperience; MobileApp Design; Wayfinding; Signaling.

\section{INTRODUÇÃO}

Este artigo apresenta os resultados do Trabalho de Conclusão de Curso intitulado IFSUL GO: Design de Aplicativo complementar ao Novo Sistema de Sinalização do IFSUL Câmpus Pelotas, que consistiu em um estudo sobre Design de Interação, Wayfinding, Experiência do Usuário e as etapas da criação de projetos para dispositivos móveis por meio da criação do aplicativo para smartphones IFSUL GO, cujo objetivo foi complementar o novo sistema de sinalização do Câmpus Pelotas do Instituto Federal de Educação, Ciência e Tecnologia Sul-rio-grandense (IFSUL), bem como trazer algumas funcionalidades para a comunidade acadêmica da instituição.

Ao chegar ao Câmpus Pelotas do IFSUL pode-se perceber uma área relativamente grande, composta por diferentes prédios localizados em um mesmo complexo que compreende, de acordo com o site ${ }^{[3]}$ oficial do Câmpus, a $48.240 \mathrm{~m}^{2} \mathrm{e}$ possui salas de aulas e laboratórios que foram construídos em diferentes momentos da instituição desde 1917, ano em que foi fundada a escolas de Artes e Ofícios, a qual passou por transformaç̃̃es em sua constituição até se tornar o que hoje é conhecido como Instituto Federal de Educação, Ciência e Tecnologia - Câmpus Pelotas.

Como servidor desde 2009 no departamento de registros acadêmicos e ainda tendo sido aluno deste Câmpus, iniciado no Ensino Médio em 2002, seguido do Curso de Graduação em Tecnologia em Sistemas para Internet e atualmente como estudante do Curso de Design - acompanho há bastante tempo a chegada de novos estudantes a cada semestre e percebo suas dificuldades para se localizarem na instituição. 
Esta localização/orientação fica ainda mais complexa quando uma série de siglas que representam diretorias, departamentos, coordenadorias, núcleos, áreas administrativas, entre outros, são apresentados aos estudantes que estão apenas começando a se ambientar com o Câmpus. Fato semelhante ocorre também com pessoas que já fazem parte da comunidade quando necessitam realizar alguma atividade atípica, mas não possuem as informações de localização e identificação necessárias para encontrar o local que procuram.

Diante desta demanda, iniciou-se o Projeto do Sistema de Sinalização do Câmpus Pelotas que foi desenvolvido inicialmente de uma parceria da Coordenadoria de Apoio a Projetos e Obras (COAPROJ) e o curso de Bacharelado em Design do Campus Pelotas no segundo semestre do ano de 2017 dentro da disciplina de Design de Sinalização, sob responsabilidade da professora Adriana da Silva.

Após o encerramento daquele semestre letivo, o projeto transformou-se em Projeto de Ensino no IFSul e Projeto de Pesquisa junto à UFPel. No ano de 2018, o projeto foi reformulado e teve como equipe projetual as estagiárias Caterine Ribeiro e Nathalia Leitzke e estudantes voluntários, orientados pela professora Dra. Andréia Bordini, da UFPel. Além disso, dispôs da coordenação e acompanhamento técnico da COAPROJ através da coordenadora Vanessa Signorini e da servidora Técnica em Edificações Arq. Camila Campelo.

Ao longo de suas diferentes fases, o Projeto do Sistema de Sinalização buscou incluir demandas e contribuições da comunidade para o seu desenvolvimento por meio de reuniões que ocorreram em dezembro de 2017, quando foi apresentado à equipe diretiva do Câmpus Pelotas e à coordenação do curso de Design, e em abril de 2018, data em que ocorreu uma apresentação à comunidade acadêmica. Além destas apresentações foi realizada em setembro de 2018 uma pesquisa com os seus usuários (alunos, professores e técnico-administrativos) por meio de um formulário pela internet. 
Mesmo não tendo participado integralmente de todas as etapas do projeto, acompanhei seu desenvolvimento, pois tive a oportunidade de contribuir como estudante do curso de Design na criação dos pictogramas desenvolvidos para o Sistema de Sinalização. Esse envolvimento com o projeto permitiu perceber que havia a possibilidade de contribuir por meio de um aplicativo que permitisse a busca e a localização de setores, blocos e salas no Câmpus, para que alunos, visitantes, técnicos administrativos e professores pudessem ter informações sobre as áreas administrativas e uma orientação inicial para chegar aos locais desejados antes mesmo de adentrar no Sistema de Sinalização.

Considerando essa possibilidade o ponto de partida para seu desenvolvimento foi a seguinte questão: Como um aplicativo poderia integrar-se ao novo Sistema de Sinalização do Campus Pelotas do IFSul a fim de auxiliar na localização dos usuários? A partir dessa questão foi estabelecido como objetivo geral projetar um aplicativo para dispositivos móveis com o intuito de oferecer uma ferramenta apropriada de apoio ao Sistema de Sinalização do Câmpus, visando auxiliar a comunidade acadêmica na localização de setores, blocos e salas, fornecendo direções e informações acerca das dependências do Câmpus.

Este Trabalho de Conclusão de Curso justificou-se, portanto, pela necessidade evidente da comunidade acadêmica do Câmpus por uma ferramenta eficaz de orientação e acredita-se que, ao apoiar o Sistema de Sinalização por meio de dispositivos móveis que detêm ampla utilização, é possível trazer uma experiência positiva de uso dos espaços para muitos indivíduos. Esta proposta está diretamente relacionada às áreas de estudo do Wayfinding, no que diz respeito à forma como as pessoas se orientam nos ambientes, bem como possui relação às áreas de Design de Informação e Experiência do Usuário voltados à utilização de interfaces digitais. 


\section{METODOLOGIA PROJETUAL}

A metodologia projetual utilizada nesta pesquisa foi uma adaptação do Design Thinking, definido por Ambrose e Harris (2011) - processo dividido em sete etapas: Definir, Pesquisar, Gerar Ideias, Testar Protótipos, Selecionar, Implementar e Aprender - que pautou o desenvolvimento do trabalho como um todo. Contudo foi também incluído o framework ${ }^{[4]}$ de Garrett (2010) a fim de compreender e arquitetar melhor questões específicas de design de interfaces tratadas pelo autor.

Essa metodologia foi utilizada por trazer uma abordagem bastante completa e estruturada que busca responder questões-chave desde a estratégia inicial até a fase de testes, podendo evoluir para um acompanhamento após a implementação do projeto de design para possíveis correções a partir do feedback dos usuários do produto.

$\mathrm{Na}$ Figura 1, pode-se melhor visualizar a estrutura da adaptação destas duas metodologias. As duas etapas finais do Design Thinking de Ambrose e Harris (2011) não foram realizadas, pois envolveria o desenvolvimento do software. Sendo assim, ressalta-se que embora o design perpasse por toda a cadeia de produção e pós-distribuição de um aplicativo, onde devem ser realizadas pesquisas de opinião e testes com os usuários para que sejam avaliados se as necessidades estão sendo atendidas, este projeto teve como foco central a fase inicial de criação da interface e protótipos, mas não adentrou na fase de Implementação.

Os Planos iniciais de Estratégia e Escopo também não foram tratados nas análises de similares pois entende-se que estes planos servem para desenvolver os conceitos e as ideias iniciais, que, em tese, já estão solucionados nestes aplicativos similares pelos designers responsáveis por suas respectivas concepções. Além disso, a inversão da ordem dos planos de Garrett na etapa Pesquisar ocorreu propositalmente para representar a ordem em que as análises dos similares ocorreram, partindo da superfície para entender a estrutura.
[4] De a acordo com ROGERS, SHARP e PREECE (2013, p. 57) um framework, no âmbito do design, serve como um modelo para ser implementado por um projetista que pode conter "etapas, perguntas, conceitos, desafios, princípios, táticas e dimensões." 

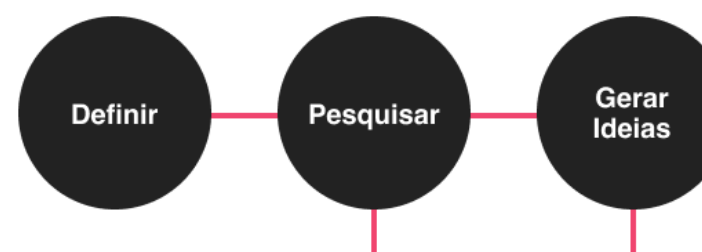

\section{Superficie}

Estratégia

\section{Esqueleto}
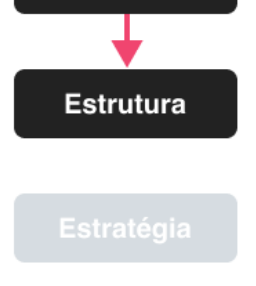

Escopo

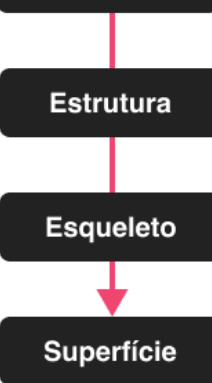

Figura 1 - Diagrama da Metodologia Projetual deste trabalho

O framework de Garrett foi utilizado em dois momentos diferentes. O primeiro na etapa Pesquisar do Design Thinking, ao analisar aplicativos similares e o segundo momento ocorreu na etapa de Gerar Ideias na parte prática de design do aplicativo. Contudo, por ser utilizado no interior de outra metodologia, ele foi adaptado conforme a necessidade, onde tanto para as análises de similares quanto para o design do aplicativo, foi focado nas ferramentas práticas sugeridas pelo autor, especialmente nos planos de Estrutura e Esqueleto, nos quais foram utilizados, respectivamente, o sitemap, que "consiste em um diagrama das páginas de um site organizadas hierarquicamente. Ajuda a visualizar a estrutura básica e a navegação entre as diferentes partes do sistema" (TEIXEIRA, 2014, p. 30) e os wireframes, cujo "maior objetivo é organizar os elementos que entrarão na composição final do design" (TEIXEIRA, 2014, p. 42), ou seja, são as telas sem a finalidade de representar fatores estéticos apenas funcionais e organizacionais dos elementos que comporão a interface do aplicativo, sistema ou site.

Por conseguinte, nas seções a seguir deste artigo, serão descritos em mais detalhes os processos que compuseram a metodologia aliada à prática projetual. 


\section{ETAPA 1: DEFINIR}

Tendo em vista que a finalidade dessa etapa é pensar sobre os conceitos que ainda estão abstratos para a equipe projetual, os autores Ambrose e Harris (2011, p.16) propõem que sejam respondidas as seguintes questões visando direcionar melhor esse momento inicial do projeto:

1. Quem é o cliente e público de interesse?

2. O que o cliente tem em mente em relação à solução de design?

3. Quando o design será necessário e por quanto tempo?

4. Onde o design será usado?

5. Por que o cliente acredita que uma

solução em design é necessária?

6. Como a solução será implementada? (op. cit., p16)

Essas questões foram respondidas tendo como elemento balizador o briefing do projeto que por sua vez foi elaborado a partir do objetivo geral do Trabalho. De acordo com Tim Brown (2019), briefing é:

[...] um conjunto de restrições mentais que proporcionam à equipe de projeto uma referência a partir da qual começar, benchmarks por meio dos quais será possível mensurar o progresso e um conjunto de objetivos a serem atingidos [...]. (op. cit., p.30)

A definição deste projeto partiu de uma demanda, cuja meta principal era a de ajudar as pessoas a se localizarem no Câmpus Pelotas do IFSUL possibilitando uma melhor experiência de interação com as dependências da instituição, e complementando o novo sistema de sinalização, principalmente, mas não somente, para aquelas que estão tendo o primeiro contato com o Câmpus. Por tanto, formatou-se o briefing do projeto da seguinte forma:

“Projetar um aplicativo para smartphones com o intuito de oferecer uma ferramenta apropriada para servir como complemento à sinalização do Câmpus Pelotas do IFSUL, visando auxiliar alunos e servidores na localização de setores, blocos e salas." 
A partir desta definição, percebeu-se que o caminho para as próximas etapas de design ficou mais objetivo e fundamentado. Ainda que alguns termos pudessem sofrer alterações conforme o andamento do projeto, deu-se andamento nas próximas etapas desta metodologia de design com a finalidade de consolidar ainda mais as ideias apresentadas.

\section{ETAPA 2: PESQUISAR}

Foram utilizadas duas ferramentas iniciais: uma coleta de dados acerca do Projeto do Sistema de Sinalização com o objetivo de obter dados relevantes de como a sinalização do Câmpus Pelotas estava sendo projetada e uma análise de similares com a intenção de obter informações de ferramentas oferecidas por uma amostra de aplicativos de Wayfinding de instituições de ensino.

Sendo assim, para a primeira parte, ocorreu a coleta de dados realizada junto à equipe responsável pelo Projeto do Sistema de Sinalização do Câmpus Pelotas, onde foi obtido acesso a documentos e informações que ainda estavam em fase de elaboração os quais continham definições sobre a Identidade Visual do sistema (como por exemplo cores, tipografia e formas que seriam utilizadas nas placas) além de aspectos funcionais do sistema de sinalização como por exemplo a divisão da área física em setores, blocos e salas para a organização do espaço e do fluxo de pessoas nas dependências da instituição (BORDINI, A., LEITZKE, N., RIBEIRO, C., 2021), reiterando ainda que fiz parte da equipe na condição de aluno voluntário para a elaboração dos pictogramas o que contribuiu para uma melhor compreensão do projeto.

Para realizar a segunda parte desta etapa Pesquisar, foi necessário definir alguns critérios de busca nas lojas de aplicativos (apps), listados a seguir:

- Os apps deveriam ser os primeiros colocados no ranking de busca pelo termo "Wayfinding" nas lojas de aplicativos. 
- Os aplicativos, além de serem ranqueados, deveriam pertencer a instituições de ensino e que tivessem o propósito central de orientar os alunos nas suas dependências.

- Os apps deveriam estar disponíveis tanto para o sistema operacional Android da Google, como do iOS da Apple, para uma aproximação maior da realidade deste projeto.

- Que fosse permitida a visualização das funcionalidades básicas sem a necessidade de efetuar um cadastro ou mesmo ser aluno/servidor da instituição.

Considerando os critérios expostos obteve-se os seguintes resultados de busca:

- Wayfinding - Da University of the West of Scotland (Universidade do Oeste da Escócia) Paisley, Escócia.

- Seneca Navigate - do College Seneca de Artes Aplicadas e Tecnologia de Toronto, Canada.

Esses apps estão disponibilizados gratuitamente na App Store e na Play Store, sem nenhuma opção de comércio no interior dos sistemas, denotando, portanto, que as instituições tinham o mesmo objetivo deste trabalho, ou seja, fornecer um serviço digital gratuito à suas respectivas comunidades fornecendo orientação no interior de suas dependências. E, ainda que indiretamente, é provável que tenham visto os apps também como uma ferramenta de marketing, já que possíveis novos alunos têm a oportunidade de obter mais informações sobre as instituições de forma virtual.

Com os aplicativos selecionados, foi iniciada a análise dos similares com a ideia de abranger duas etapas:

- A primeira etapa é uma análise da interface dos aplicativos, que evidenciou algumas escolhas de design visual. 
- A segunda é a descrição da navegação de cada aplicativo, que forneceu a Arquitetura da Informação, servindo como uma atividade de reconhecimento dos apps.

Essas etapas, de certa forma, podem ser identificadas no framework de Garrett (2010) sendo que a primeira seção se encaixa no Plano de Estrutura e a segunda nos Planos de Esqueleto e de Superfície. No entanto, esta pesquisa foi realizada na ordem reversa dos Planos de Garrett (sem utilizar os Planos Estratégia e Escopo) uma vez que iniciou-se analisando a superfície, passando para o esqueleto e terminando na estrutura, similar ao que seria a engenharia reversa ${ }^{[5]}$.

Para a análise do Plano de Superfície, tendo em vista que os aplicativos selecionados estão disponíveis tanto para iOS quanto para Android, utilizou-se como referência o documento de diretrizes oferecido pelo Google (Material Design) por se propor a ser um sistema de design que independe da plataforma digital que será implementada. Contudo, por ser um documento com grande densidade de conteúdo, foi utilizado apenas nos quesitos: paleta de cores, iconografia e elementos de interface, que terão mais relevância na geração de ideias. Todavia, essas diretrizes serviram para as análises apenas como um guia de boas práticas de Design, uma vez que nenhum dos desenvolvedores dos produtos se pronunciam a respeito de como estes foram projetados.

No Plano de Esqueleto, cada app foi revisado a partir da observação dos prints das principais telas, com o objetivo de entender as escolhas de layout dos designers que também possibilitaram, através da abstração de navegação, obter o sitemap representando o plano de estrutura.

O resultado mais aprofundado dessas análises serviu como um exercício de reconhecimento inicial, conduzido com o propósito de buscar funcionalidades e elementos que tivessem o potencial de trazer insights para o aplicativo de Sinalização do Câmpus Pelotas do IFSUL criando um ponto
[5] De acordo com Moura (2021) "Engenharia Reversa é o processo de descobrir os princípios tecnológicos e o funcionamento de um dispositivo, objeto ou sistema, através da análise de sua estrutura, função e operação. Objetivamente a Engenharia Reversa consiste em, por exemplo, desmontar uma máquina para descobrir como ela funciona." 
de partida para as próximas etapas, bem como fundamentando as escolhas de design para este projeto. Um exemplo, das etapas da análise de engenharia reversa dos planos de Garrett (2010) aplicadas no aplicativo Seneca Navigade pode ser verificado na Figura 2.

\section{SUPERFICIE}

\section{ESQUELETO}

\section{ESTRUTURA}
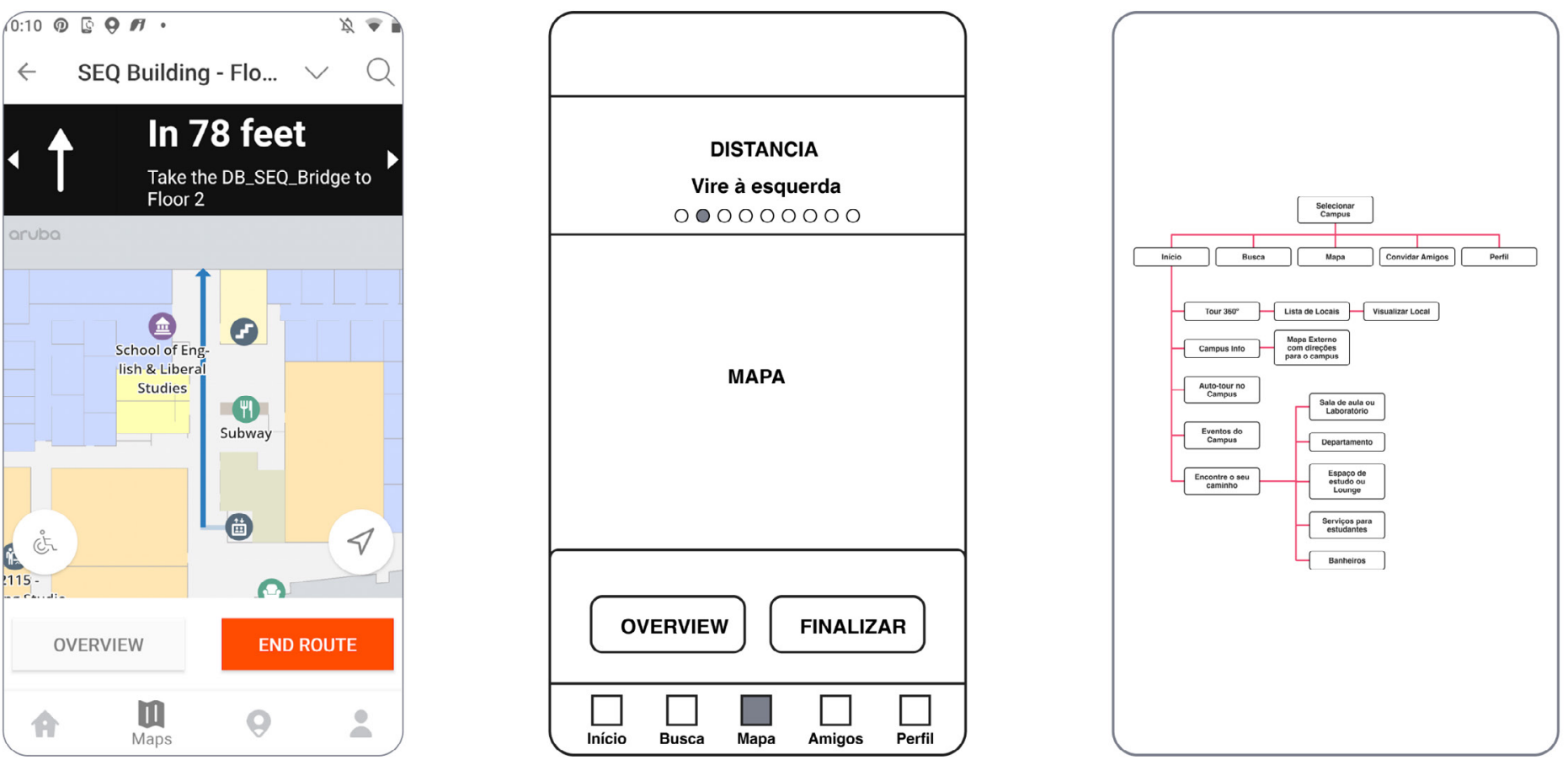

Figura 2 - Exemplo das etapas de análise do aplicativo similar Seneca Navigate. Fonte: do autor. 
Após realizada essa investigação com o intuito de explorar os apps para analisar quais seriam os seus atributos estéticos e funcionais, foi possível identificar e avaliar possíveis recursos a serem incluídos no aplicativo IFSUL GO, tornando a próxima etapa, de Gerar ideias, menos abstrata por ter como se basear em casos de uso reais de instituições de ensino.

\section{ETAPA 3: GERAR IDEIAS}

A terceira etapa do Design Thinking é o momento em que o designer busca gerar conceitos que serão desenvolvidos para obter o produto desejado. Segundo Ambrose e Harris (2011) "durante esta fase, a equipe de design se debruça sobre as informações coletadas na pesquisa e as restrições estabelecidas durante a etapa de definição para gerar ideias que atendam ao briefing de design." (op. cit., p. 20)

No entanto, apesar de ser um momento de liberar a criatividade, no caso deste trabalho, esta atividade ocorreu de forma mais estruturada, por se tratar de um produto complexo que deve cumprir uma série de requisitos funcionais. Para tanto, foi utilizado novamente o framework de Garrett (2010), desta vez seguindo os planos - plano de estratégia, plano de escopo, plano de estrutura, plano de esqueleto, e plano de superfície - na ordem em que o autor propõe, também de forma pragmática por meio de ferramentas específicas que ajudaram a compor cada plano os quais serão descritos a seguir.

\section{PLANO DE ESTRATÉGIA}

No Plano de Estratégia, Garrett (2010) defende que seja feita uma segmentação da audiência do produto para melhor entender as necessidades de cada grupo e sugere ainda que, após esta divisão, sejam criadas personas como ferramenta para orientar a conceituação inicial do produto.

Levando em consideração que o público-alvo deste trabalho é composto por visitantes, técnico-administrativos, professores e alunos, foram elaborados personagens fictícios para cada uma dessas categorias onde buscou-se sintetizar 
o que cada indivíduo necessitaria realizar de atividade que seria relevante para a concepção do aplicativo.

Como exemplo pode-se citar a persona Murilo Tucker, professor da área de Formação-Geral, que leciona em diversos cursos situados em diferentes prédios do Câmpus e tem a necessidade de se locomover para as salas entre uma aula e outra de forma eficiente, sendo capaz de comunicar para a turma alguns imprevistos como, por exemplo, a troca de sala quando a programada estiver ocupada por outro professor.

Este exercício de empatia realizado para cada um dos tipos de usuários através da criação de personagens fictícios possibilitou visualizar as necessidade de diferentes ângulos, além de confirmar que ferramentas digitais poderiam trazer ainda mais independência para os seus usuários na forma de complemento da sinalização e ajudou a criar um foco ainda maior nas funcionalidades relevantes para serem projetadas para o IFSUL GO.

\section{PLANO DE ESCOPO}

Segundo Garrett (2010), "estratégia se torna escopo quando você traduz as necessidades dos usuários e os objetivos do produto em requisitos específicos para o conteúdo e as funcionalidades que o produto vai oferecer para o usuário." (op. cit., p. 57)

Sendo assim, além da definição da audiência por meio de personas, as coletas de informações realizadas nas etapas de briefing e pesquisa do Design Thinking ajudaram a conceber o plano de escopo que, como definido anteriormente, pode ser representado por um documento contendo os requisitos para o desenvolvimento do produto digital.

Os requisitos abordados no referido documento abordaram questões como por exemplo:

- Paleta de Cores do Sistema de Sinalização do Câmpus: O Verde, o Laranja e o Roxo foram idealizadas pela equipe com a finalidade de 
representar os diferentes setores do Câmpus

Pelotas, devendo portanto serem utilizadas

exclusivamente para este fim.

- Representação de locais no Sistema de Sinalização:

Os locais representados no app devem ser exibidos em coerência com as definições do projeto de sinalização, contendo a cor do setor, a letra do alfabeto latino que representa o bloco e o número da sala.

- Recursos imprescindíveis do IFSUL GO: Disponibilizar o mapa do Câmpus com a possibilidade de traçar rotas, disponibilizar um sistema de leitura de $Q R$-Code exibindo informações dos locais e apresentar uma solução para que os professores e os alunos tenham acesso a seus horários de aula e atividades acadêmicas.

- Restrições do IFSUL GO: Projetar um aplicativo que seja o mais independente possível dos demais sistemas acadêmicos da Instituição, uma vez que este é um trabalho acadêmico e que futuramente, caso seja implementado, não necessite obrigatoriamente de autorização para acesso aos bancos de dados oficiais.

A partir destas definições detalhadas no documento de requisitos do Plano de Escopo, muitas dúvidas que ainda estavam abstratas foram solucionadas o que permitiu seguir para o próximo plano com um direcionamento maior de quais páginas seriam construídas para contemplar os recursos necessários.

\section{PLANO DE ESTRUTURA}

O Plano de Estrutura, passou a ser a concretização dos requisitos compilados nos planos de Estratégia e Escopo, onde as telas do aplicativo passaram a ser representadas em um estudo de Arquitetura de Informação, que resultou na construção básica do sitemap o qual foi sendo incrementado ao longo do projeto. 
Além dos recursos principais do app, no sitemap existe também a representação de qual tipo de usuário tem permissão para utilizar determinada funcionalidade, visto que algumas possuem restrição de acesso. Por conseguinte, essa representação foi feita pela letra inicial de cada tipo de usuário, sendo V para Visitantes, P para Professores e A para Alunos.

Esta estrutura proporcionou uma visão ampla e mais concreta das necessidades de concepção de cada tela. Parte de como ficou o sitemap pode ser conferido na Figura 3.
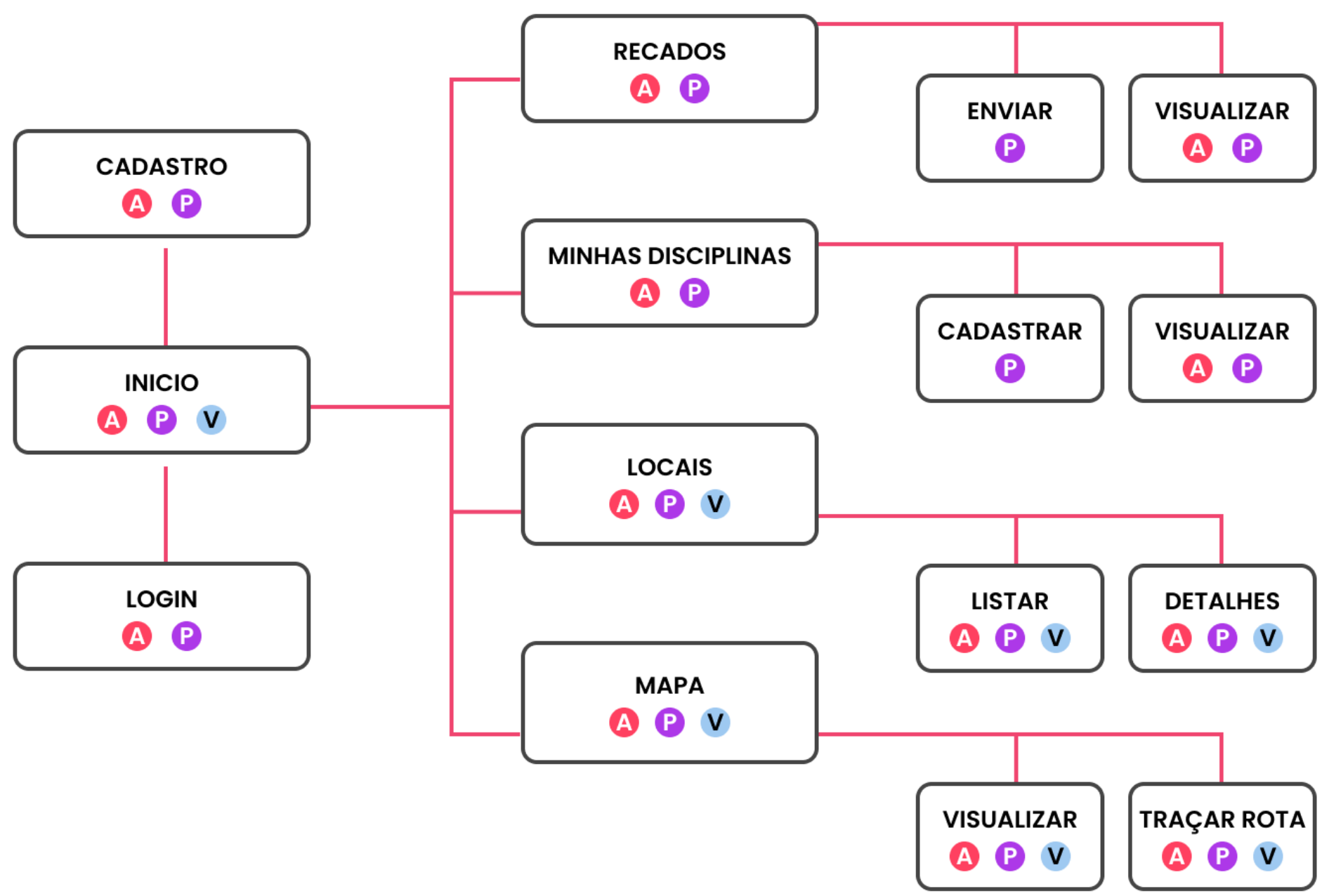


\section{PLANO DE ESQUELETO}

Enquanto o Plano da Estrutura lida com questões de macro interação dentro de um sistema, atendo-se a estrutura do fluxo de informação e a navegação de página em página, o Plano de Esqueleto trata de colocar em evidência os pontos inerentes ao layout de cada uma dessas páginas, assim como o comportamento dos elementos de interface.

O Plano de Esqueleto foi tratado nesta pesquisa a partir da construção dos wireframes, com o objetivo de representar os elementos que compõe a interface de cada tela e conectá-las em forma de protótipo básico para verificar, na medida em que estavam sendo criadas, se o fluxo de navegação fazia sentido.

É importante ressaltar que, neste projeto, apesar de buscar ser o mais preciso possível, tanto os wireframes quanto o sitemap não tiveram a pretensão de documentar com exatidão o aplicativo final, mas sim servirem de base para fundamentar cada passo seguinte. Dessa maneira, as Figuras 4, 5 e 6 contém as principais telas do app no formato de wireframe.
Figura 4 - Wireframes das Telas Home, Locais e Agenda. Fonte: do autor.
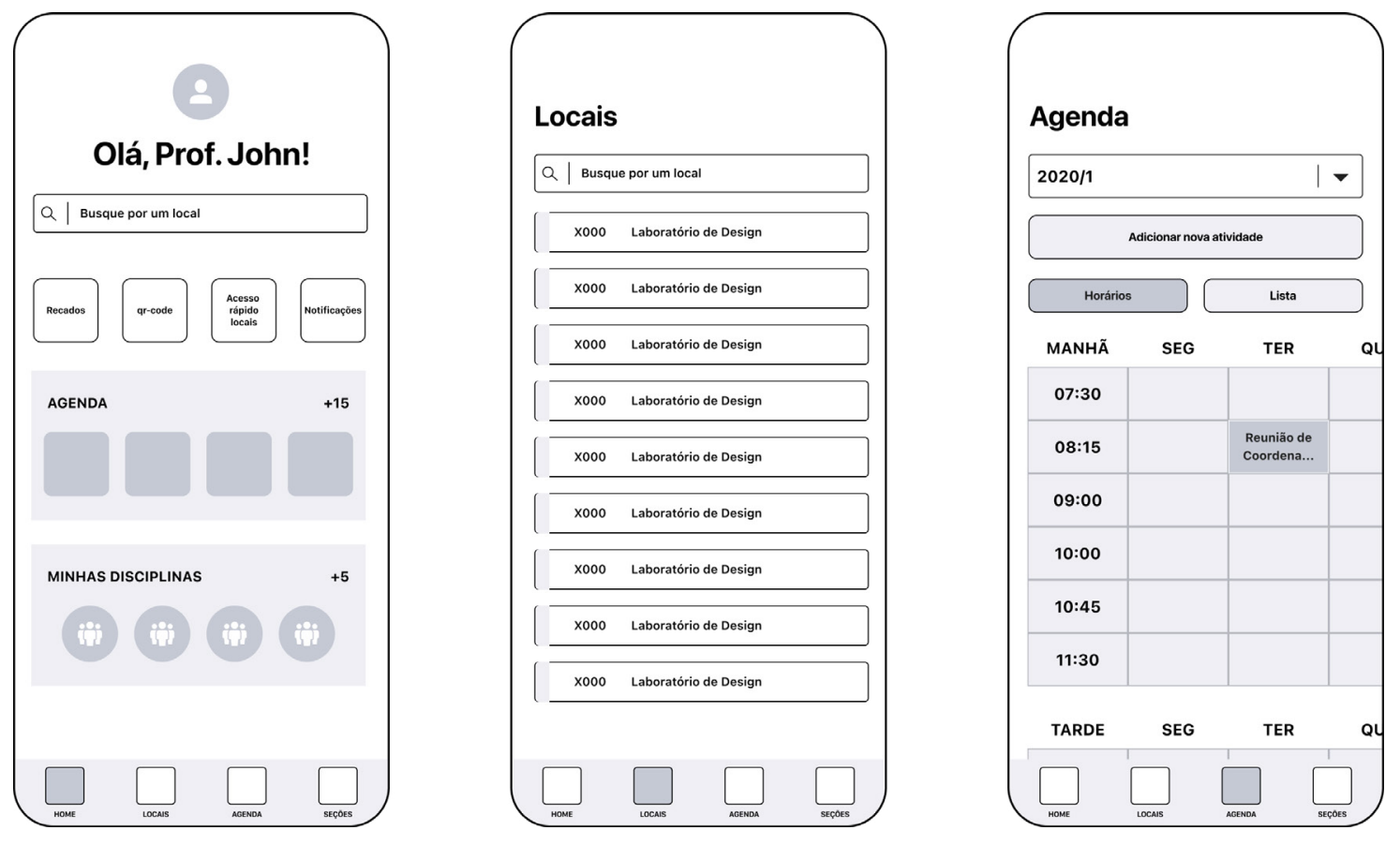

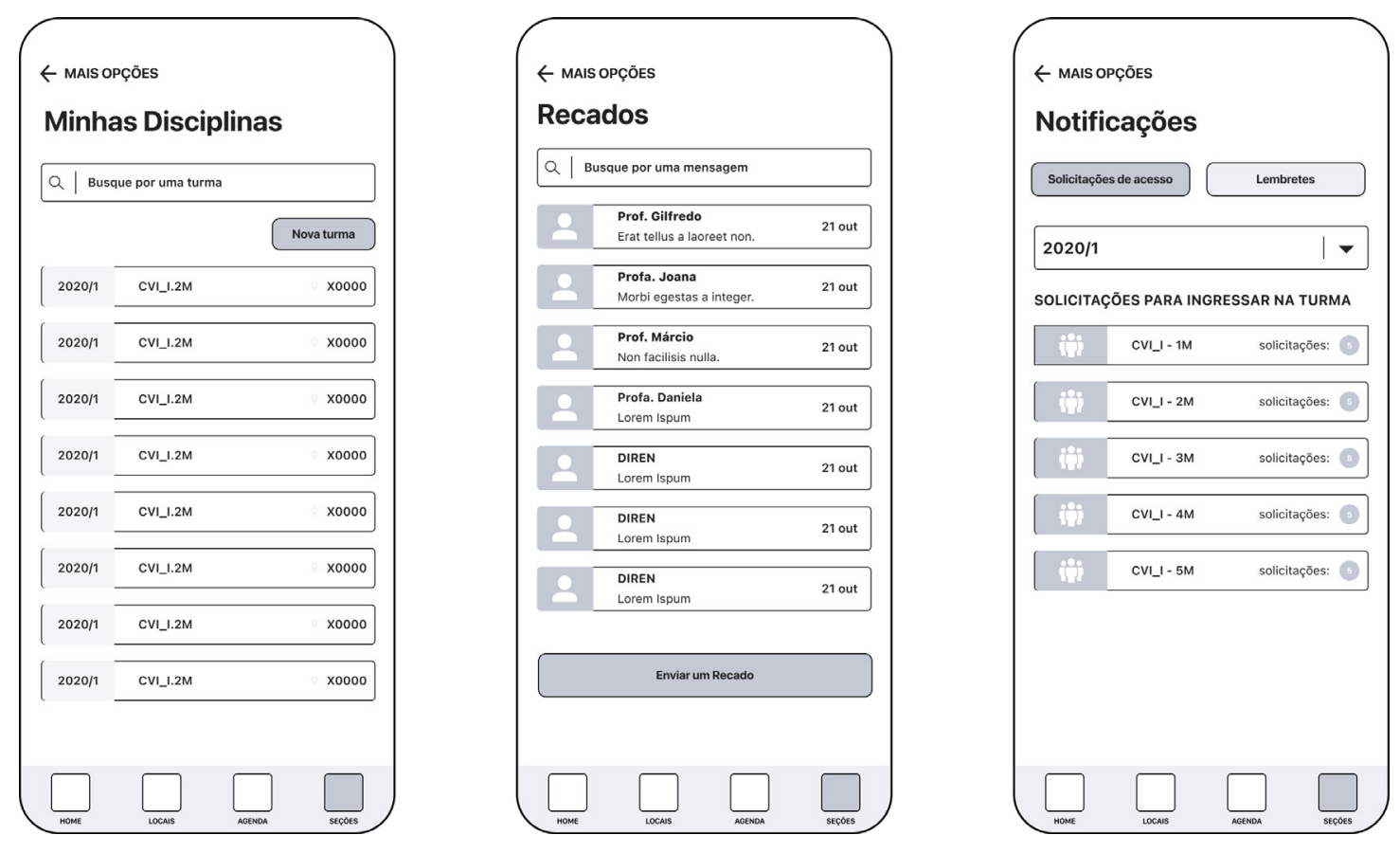

Figura 5 - Wireframes das telas mais opções, mapa e QR-Code. Fonte: do autor.
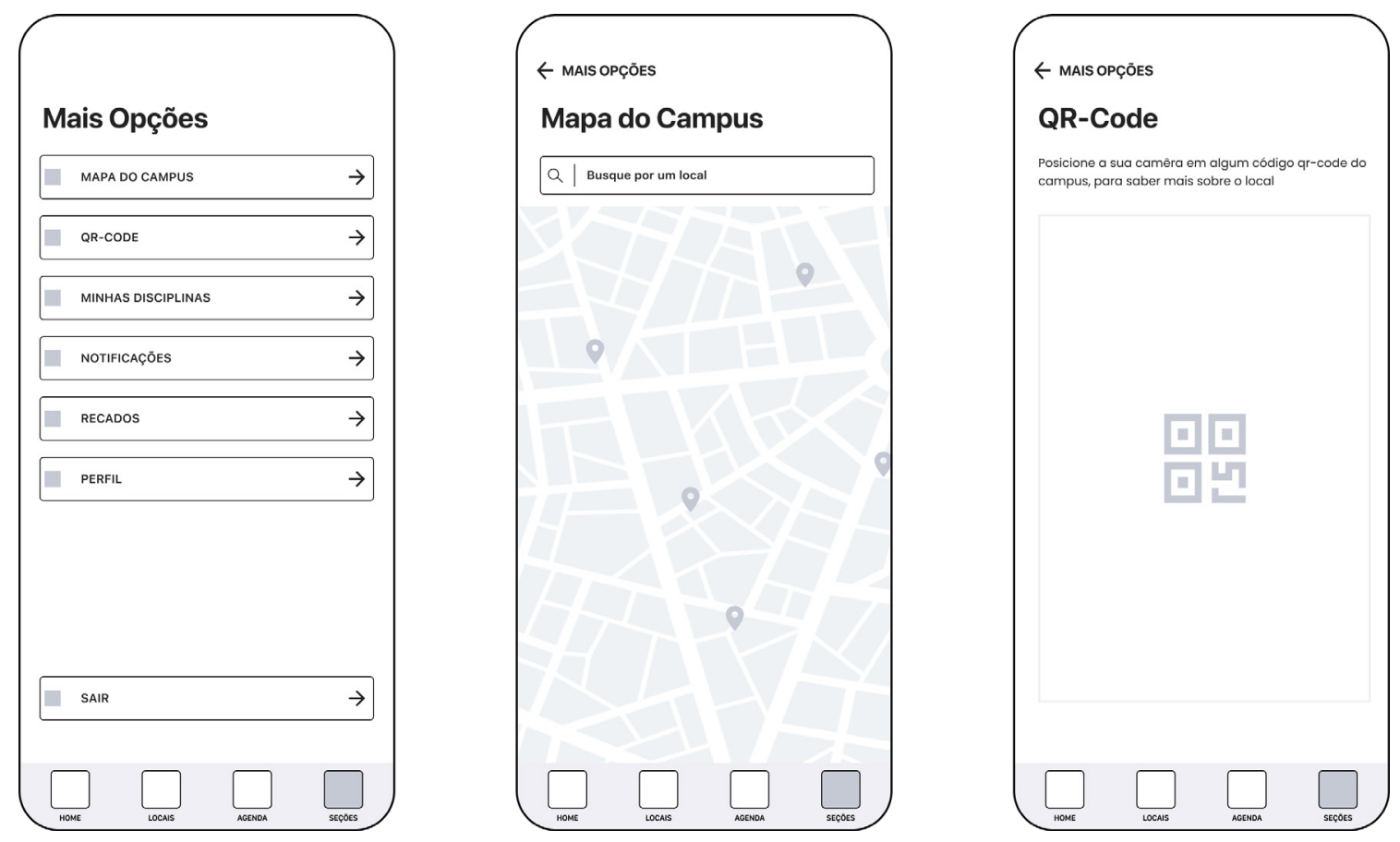

Figura 6 - Wireframes das telas Minhas disciplinas, Notificações e Recados. Fonte: do autor: 
Para fins de esclarecimento, é importante destacar que as funcionalidades não foram concebidas com o intuito de substituir os sistemas acadêmicos da Instituição, mas sim servir como uma ferramenta extra para o usuário se organizar e se localizar na instituição.

À medida que as telas de wireframe do Plano de Esqueleto foram sendo criadas, consequentemente surgiram as questões (problemas) inerentes à interação do usuário com a interface. O método utilizado para abordar estes problemas foi o de idealizar as possíveis soluções em uma dinâmica de produção, testes, sugestões e ajustes. Esta dinâmica seguiu no plano seguinte onde as telas foram desenhadas com o intuito de finalizar a primeira versão do projeto de design.

\section{PLANO DE SUPERFÍCIE}

É nesta fase que questões gráficas e sensoriais passam a figurar, sendo o Plano de Superfície a união entre "conteúdo, funcionalidade e estética" (GARRETT, 2010, p. 133), com a finalidade de apresentar o produto para que desenvolvedores possam começar a construir as páginas conforme as especificações.

Com os wireframes e o fluxo das telas definidos, o Plano de Superfície foi abordado como a intenção de compor as telas utilizando os elementos visuais finais da primeira versão do app, aperfeiçoar as interações e obter um protótipo que simulasse o mais próximo possível de como o aplicativo deverá funcionar.

Neste plano, ocorre uma exploração maior do conceito geral do que é a etapa Gerar Ideias, visto que aqui existe a oportunidade de criar muitas alternativas para que se ter uma visão clara da direção do app. Para melhor elucidar o desenvolvimento do Plano de Superfície, esta seção foi dividida em seis partes: tipografia, paleta de cores, ícone do aplicativo, layout, componentes de interface e telas finais. 


\section{TIPOGRAFIA}

Na escolha da fonte houve uma preocupação em procurar uma tipografia que tivesse boa legibilidade e leiturabilidade, que segundo Jen \& Ken O'Grady (2008), se referem, respectivamente, a clareza e rapidez que um conteúdo pode ser lido e ao nível de reconhecimento da forma de letras e palavras, ou seja, uma tipografia que fosse fácil de ler tanto em títulos como em textos em um contexto de dispositivos móveis que têm a tela relativamente pequena. Para garantir isso, foram considerados os seguintes fatores sugeridos pelos autores Jen O'Grady \& Ken O'Grady (2008): equilíbrio entre forma e contraforma; altura-x (altura do corpo principal das letras minúsculas de uma tipografia); balanço entre largura e altura e kerning (espaço entre duas letras) e tracking (espaço entre as letras em uma palavra, linha, parágrafo ou texto).

Além disso, outro fator ponderado foi a variedade de pesos da fonte, que é a relação entre a largura e altura da linha criada para reproduzir as letras da tipografia (O'GRADY e O'GRADY, 2008), por exemplo, negrito, normal, leve etc. Essa diversidade permite que seja utilizada a mesma tipografia para estabelecer uma hierarquia de informações na tela diferenciando títulos e subtítulos de textos. Dessa forma, ao buscar uma fonte gratuita que satisfizesse esses requisitos, foi selecionada a família de tipos Poppins, criada pela companhia Indian Type Foundry disponível no website Google Fontes. Com características de uma fonte geométrica e sem serifa, disponibilizada em até dezoito variações de peso e estilo. Uma demonstração desta fonte pode ser visualizada na Figura 7.

The quick brown fox jumps over the lazy dog

The quick brown fox jumps over the lazy dog

The quick brown fox jumps over the lazy dog

The quick brown fox jumps over the lazy dog

The quick brown fox jumps over the lazy dog

The quick brown fox jumps over the lazy dog

Figura 7 - Fonte Poppins selecionada para o app. Fonte: do autor. 


\section{PALETA DE CORES}

Durante este processo o princípio que serviu de guia para a produção dessas telas, em termos de paleta de cores, foi a ideia de que esta deveria harmonizar com as principais cores definidas no novo Sistema de sinalização, que divide o Câmpus em três grandes setores, a qual cada um é representado por uma diferente cor (verde, laranja e roxo) e as cores cinza e branco também presentes, mas como auxiliares nas placas.

Considerando a importância destas três cores para o processo de Wayfinding no interior da instituição, e atendendo a uma tendência inclinação de se oferecer além temas claros (light), também os temas escuros (dark) no design de aplicativos, foi criada uma paleta (Figura 8) utilizando como protagonistas as cores dos setores do Câmpus e com as devidas variações de acordo com os temas dark e light, considerando o contraste entre o fundo e as cores utilizadas para uma boa legibilidade.

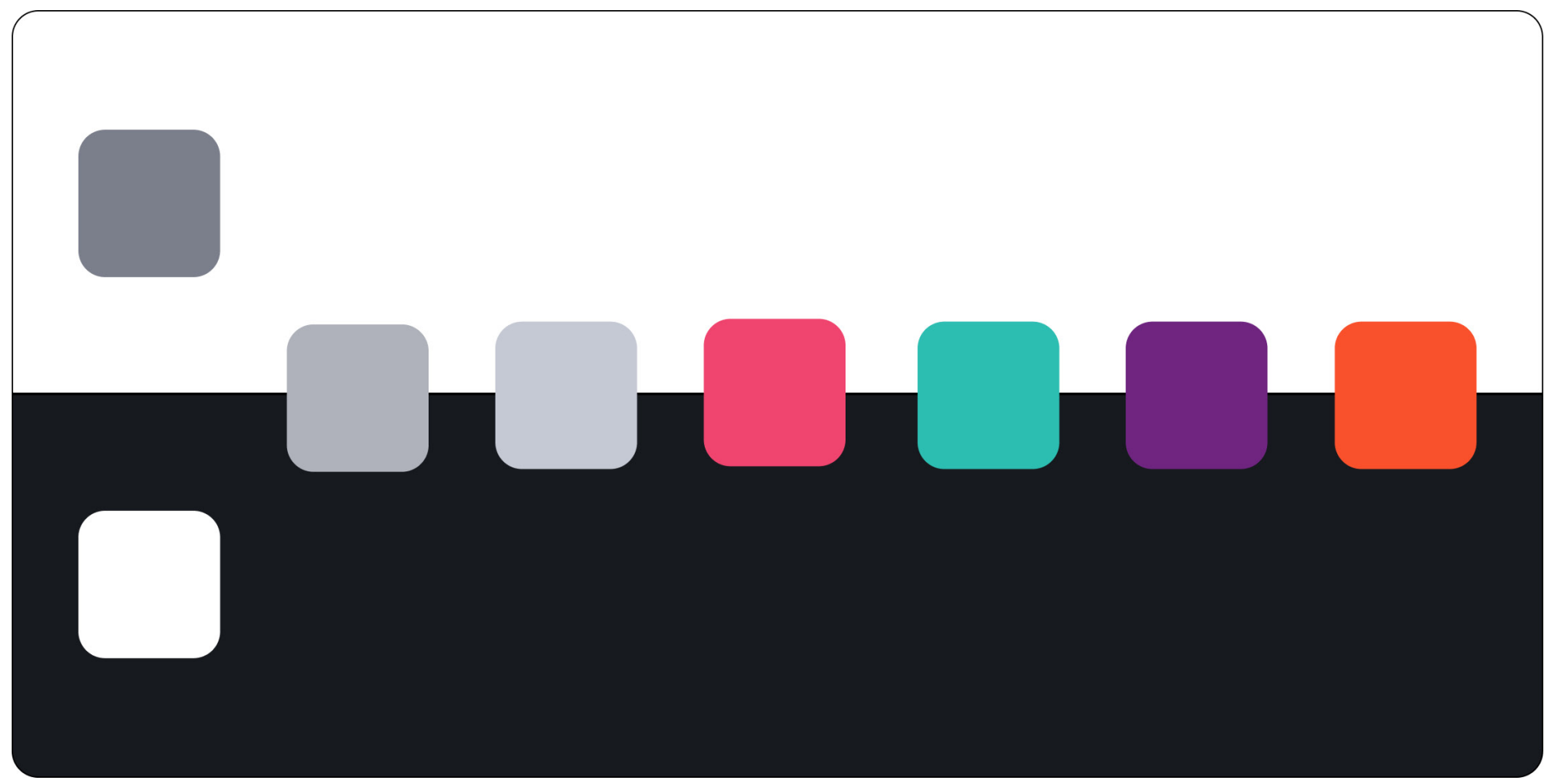




\section{ÍCONE DO APLICATIVO}

Em um primeiro momento foi pensado desenvolver um logotipo "definido como um símbolo representando uma frase, uma palavra ou uma ideia" (DOUGLAS, 2011, p. 7) como um elemento de Identidade Visual desassociado do ícone, ou seja, a partir do logotipo, seria extraído o ícone, mas eles não seriam necessariamente iguais. Isso levou a produção de algumas ideias cujo comprimento era relativamente extenso.

Após esses testes seguiu-se uma busca por um nome mais curto do que os anteriores e chegou-se ao nome IFSUL GO. Utilizando a palavra $G O$ (do inglês verbo ir) juntamente com IFSUL, cria-se uma sugestão do que trata-se o app, bem como associa-se a um nome de um jogo bastante famoso chamado Pokémon GO, um app em que alunos jogadores andavam pelo IFSUL à procura de personagens do jogo utilizando a realidade aumentada.

Sendo assim, a solução final para o ícone apresentada na Figura 9, foi o resultado de uma simplificação dos ícones gerados anteriormente, onde foi utilizada apenas a palavra GO com uma tipografia criada pelo autor, a partir de formas geométricas, com o símbolo que representa direcionamento circunscrito na letra "O".

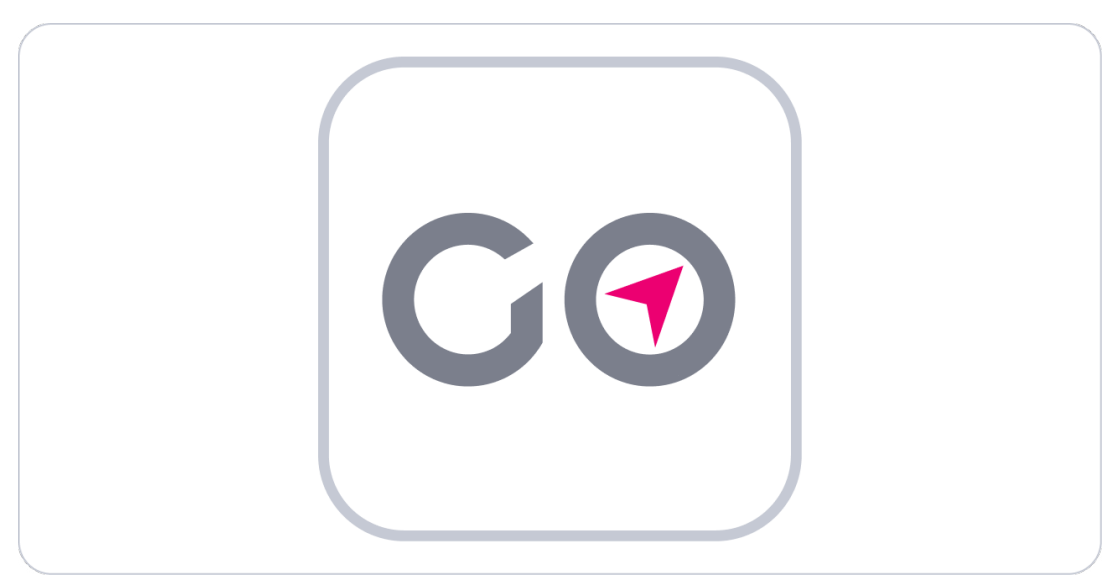

Figura 9 - Ícone final do app IFSUL GO. Fonte: do autor. 


\section{LAYOUT}

Em razão de que cada tela de dispositivo possuir uma dimensão diferente sem seguir um padrão de escala entre elas e muitos elementos possuem tamanhos fixos em unidades de pixel, não houve uma preocupação em encaixar os componentes da interface em uma grade, mas sim distribui-los de forma consistente e harmônica com o auxílio do software, pois, na prática, o desenvolvedor fará o mesmo na hora da implementação.

Para o layout, a aplicação do grid ocorreu mais em espaçamentos e dimensões escaláveis de 8 em 8 unidades (pixel) que é o padrão sugerido pela Apple e pela Google com o intuito de manter a consistência por todo o design.

Por exemplo, na Figura 10, o menu principal pode ser visualizado aplicado em uma tela de iPhone $X$ de $375 p x$ de largura (à esquerda) e uma tela de Android Pixel 2 de 411 px de largura (à direita), onde ambos respeitam as margens de segurança de $16 \mathrm{px}$ e possuem botões com uma área de toque no tamanho fixo de 48px. Evidentemente, neste caso, seria impossível de encaixar os elementos em um único grid convencional já que o corpo da tela deve ser fluido para se adaptar aos diferentes aparelhos de usuários.

Figura 10 - Menu aplicado em uma tela de iPhone X e Android Pixel 2. Fonte: do autor.
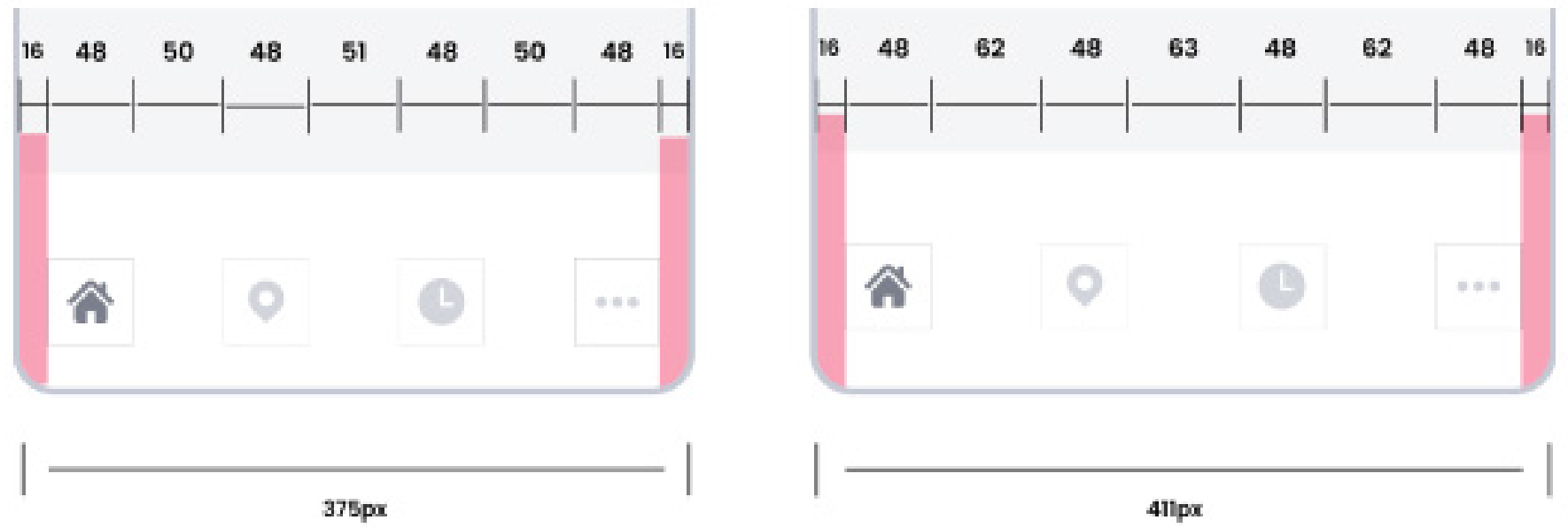


\section{COMPONENTES DE INTERFACE}

Desde o princípio do Plano de Superfície, foi buscado desenvolver componentes de interface reutilizáveis, como por exemplo, cabeçalhos, botões, formulários, tipos de listas, tipos de textos e suas respectivas variações, que foram sendo gradativamente documentados no software de design e replicados durante o processo de criação das telas.

O software utilizado para projetar todo o aplicativo, desde o sitemap até o protótipo final, o Figma, cujos recursos voltados para criação de componentes de interface permitiram criar uma biblioteca em que cada um de seus elementos fossem projetados juntamente com suas variações.

Na Figura 11, pode ser visualizado um componente que representa uma linha de uma lista de recados; este componente possui duas propriedades com duas variações cada: Esquema de cores (Light ou Dark) e estado de visualização do recado (Visualizado ou Não Visualizado).
Figura 11 - Componentes de lista de recados e suas variações. Fonte: do autor.
Dark Mode $=$ Não, Visualizada $=$ Não

Arlene McCoy

Pellentesque ultricies velit accumsan.
Dark Mode $=$ Sim, Visualizada $=$ Não

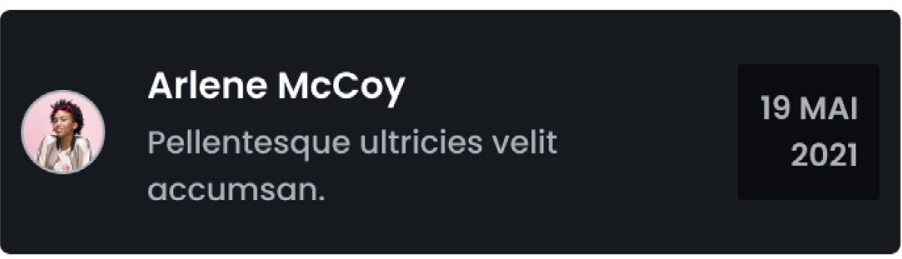

Dark Mode $=$ Sim, Visualizada $=$ Sim

Dark Mode $=$ Não, Visualizada $=\operatorname{Sim}$

Arlene McCoy

Pellentesque ultricies velit

$19 \mathrm{MAl}$

2021
19 MAI

2021
Arlene McCoy

Pellentesque ultricies velit accumsan. 
Segundo o website PCMag ${ }^{[6]}$ (2021), o resultado da combinação dos valores originais de um objeto (neste caso um componente) com as diferentes variações, é considerado um estado. Conforme cada elemento ia sendo inserido e definido no layout, a partir do projeto do tema claro, eram identificados os componentes que poderiam ser replicados e construídos definindo seus diferentes estados.

Ao longo desse processo, essa atividade foi demonstrando suas vantagens já que aos poucos a criação de novas telas foi sendo otimizada (inclusive do tema escuro inteiro), assim como a consistência do design como um todo foi favorecida, em virtude dos componentes principais estarem localizados em uma biblioteca e quando alguma propriedade destes necessitou ser modificada, havia uma alteração nesta automaticamente em todas as instâncias que o respectivo componente foi replicado.

\section{TELAS FINAIS}

Seguindo as diretrizes de cores e tipografia da identidade visual do IFSUL GO, as telas foram construídas de forma incremental, onde ajustes pontuais no layout foram sendo feitos eram refletidas sobre as decisões de design feitas nos wireframes.

Essas reflexões, não foram somente propiciadas para poder enxergar uma interface mais fiel à realidade do app, mas também pelo fato de concomitantemente com a construção dos layouts, as telas terem sido conectadas formando o protótipo a fim de simular a resposta de cada elemento frente ao comportamento do usuário.

Foram projetadas telas de seções como: Onboarding, Cadastro e Login, Tela Inicial e Menu de Acesso Rápido, Telas de Localização, Agenda, Minhas Disciplinas, Recados, Notificações, Perfil. $\mathrm{Na}$ figura 12, pode ser verificada uma amostra das telas finais.

Após a criação de todas as telas no tema Claro e, simultaneamente, criado os componentes e seus respectivos nos dois temas (Claro e Escuro), foram duplicadas todas as telas e, passo a passo, alterado o estado dos componentes com objetivo de converter o protótipo para a o tema escuro. Um exemplo do resultado final deste protótipo na versão escura pode ser visualizado Figura 13. 

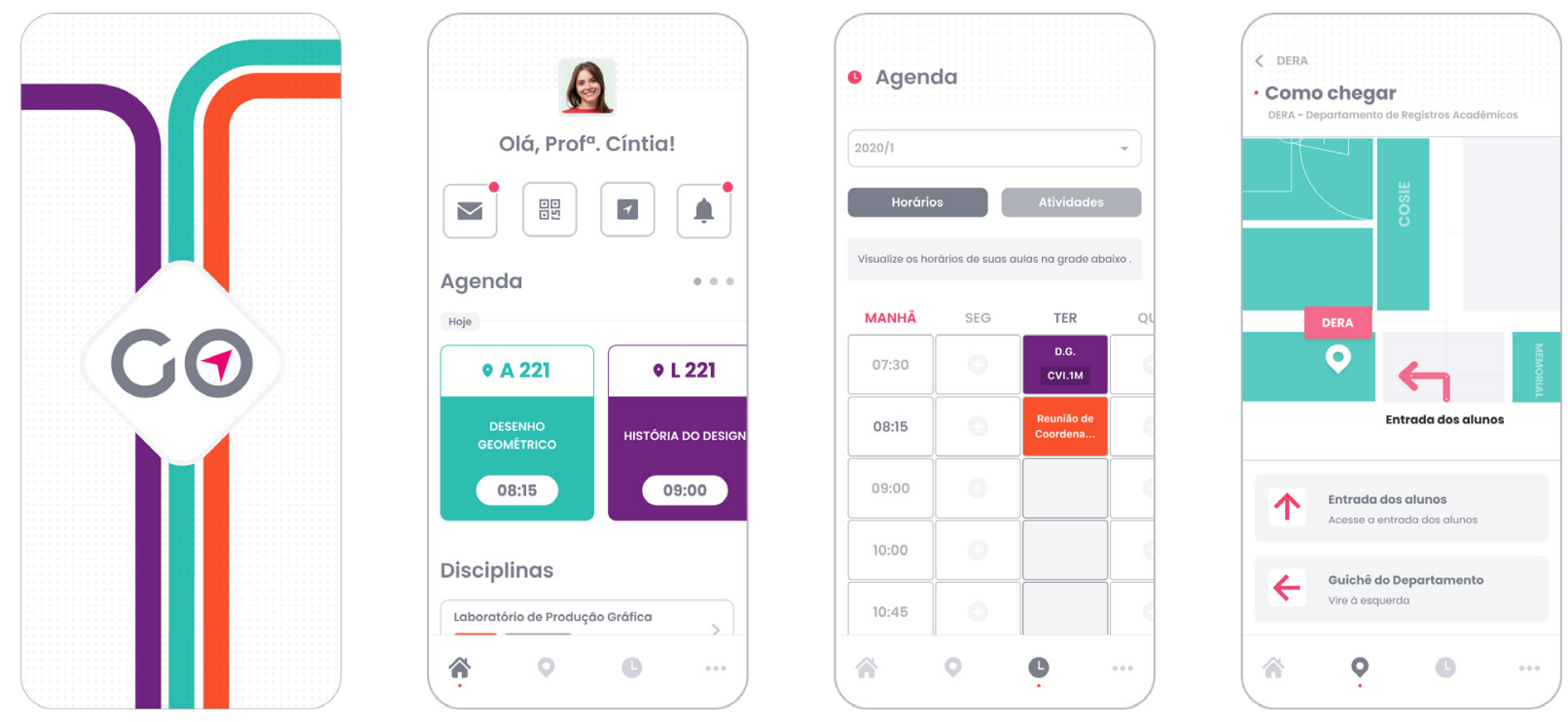

Figura 12 - Telas Light: Splash, Inicial, Horários e Como chegar. Fonte: do autor.
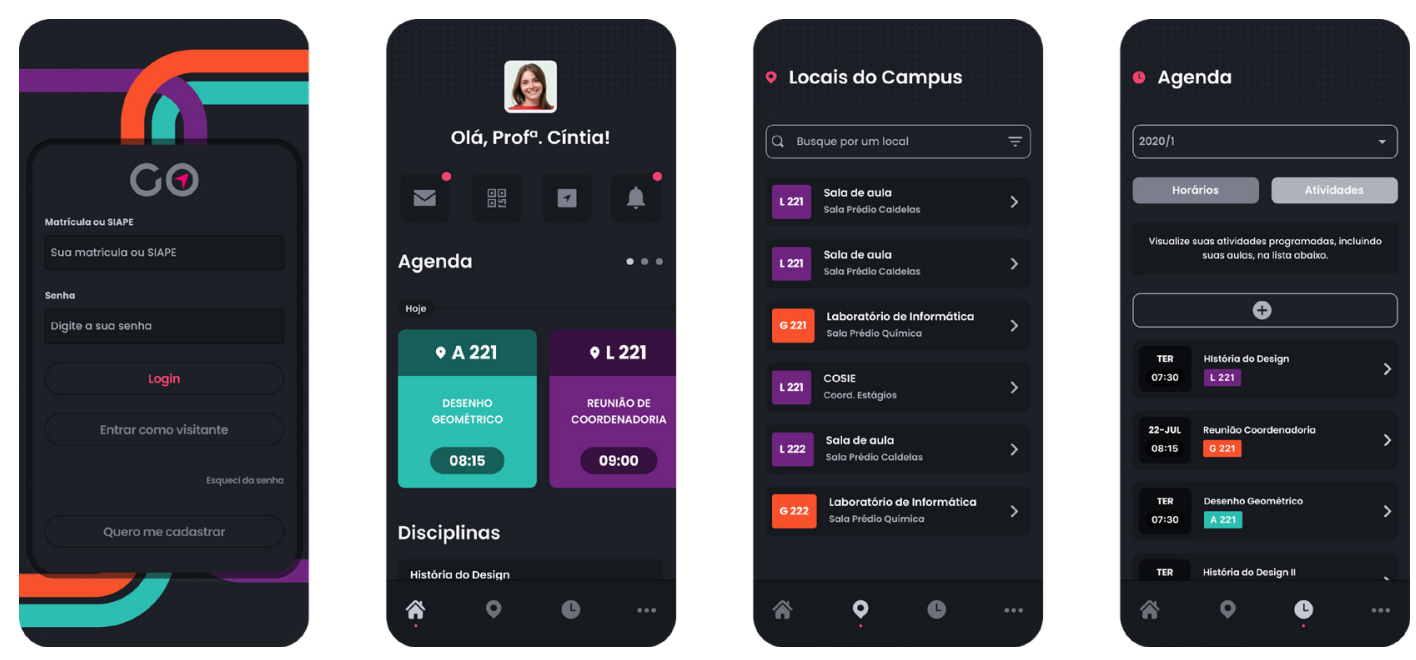

Figura 13 - Telas Dark: Login, Inicial, Locais e

Lista de Atividades. Fonte: do autor. 


\section{ETAPA 4: TESTAR PROTÓTIPOS}

Na etapa de Gerar Ideias, de Ambrose e Harris (2011), uma série de soluções para o problema devem ser elaboradas para que os protótipos sejam produzidos, testados e a equipe projetual tenha uma base de dados para fundamentar as suas escolhas. Entretanto, como no IFSUL GO foi utilizado o framework de planos do Garrett (2010), ocorreu um estudo para obter uma única solução paralelamente aos processos de geração de ideias, resultando no protótipo do app.

Sendo assim, nesta Etapa 4, Testar Protótipos, ao invés de testar vários conceitos como o sugerido por Ambrose e Harris (2011), a abordagem que foi feita através de um teste de usabilidade com as telas desenhadas do IFSUL GO para identificar os pontos que necessitavam ser melhorados antes da etapa de implementação. Em conformidade com Teixeira (2014) "Testes de usabilidade têm por objetivo verificar a facilidade que o software ou site possui de ser claramente compreendido e manipulado pelo usuário" (p. 135).

Por conseguinte, foi elaborado um conjunto de tarefas para serem executadas na interface do app e enviado para possíveis participantes ${ }^{[7]}$ juntamente com o link do protótipo e um questionário retirado do site usability.gov, do governo dos Estados Unidos, que propõe o uso do SUS (System Usability Scale), que é um Sistema de Escala de Usabilidade originalmente criado por John Brooke em 1986, e permite avaliar uma série de produtos, incluindo aplicativos móveis.

O questionário possuía dez afirmações sobre o uso de sistema testado em que os participantes devem informar, em uma escala de 1 a 5, o quanto concordam com aquela afirmação. Segundo, o website usability.gov esse sistema se tornou um "padrão para a indústria e possui referências em mais de 1300 artigos e publicações" (USABILITY, 2021).

Marianne Braum (2019) escreveu um artigo publicado no UX Collective ${ }^{[8]}$ (2019) - website dedicado a fazer uma curadoria de artigos de design de experiência do usuário - explicando como obter os resultados da pontuação do teste na
[7] Os participantes selecionados foram alunos, professores e técnicosadministrativos do IFSUL, abordados diretamente por mim, através de aplicativo de mensagem sem um pareamento dos tipos de usuário, visto que a intenção era apenas testar a usabilidade do app neste momento.

[8] Disponível em: <https:// bit.ly/3yGFgDg $>$ Acesso em: 20 jul. 2021 
prática. De acordo com Braum (2019) a média do resultado é de 68 pontos e se estiver abaixo dessa pontuação o produto teria problemas sérios a serem resolvidos.

Devido à quantidade de telas interconectadas e provavelmente em razão de limitações ou problemas técnicos de performance do próprio software de prototipagem utilizado (Figma), durante o período de testes recebi relatos de que este não estava carregando, ou que, após o seu carregamento, o protótipo ou até mesmo o computador do participante estavam travando, o que pode ter influenciado bastante na quantidade de respostas que foi pouca, tendo um total de cinco participantes.

No entanto, Teixeira (2014) afirma que não é necessário que os testes sejam feitos com muitos participantes, podendo ser de 3 a 5, e complementou que "a coisa mais importante é testar com pessoas que usariam o serviço. O perfil demográfico pode ser aproximado" (p.138), o que, de certa forma, valida esta etapa do Design Thinking, já que a pesquisa contou com cinco participantes.

A média total da pesquisa feita com os 5 participantes foi de 98,5 pontos, considerando que pontuação máxima era 100 pontos. Nesse período de testes não foram obtidos resultados específicos o suficiente que justificassem uma modificação no design das telas. Isso pode ser reflexo de terem ocorrido de forma assíncrona, ou seja, o participante fez o teste sozinho sem a minha presença, me impedindo, talvez, de captar algumas dificuldades sobre as quais ele não se manifestou.

De qualquer forma, conforme Ambrose e Harris (2011), durante a etapa Aprender, que ocorre após a etapa de Implementação, a qual não foram tratadas nesta pesquisa, os usuários tendem a fornecer um feedback em relação ao produto, e consequentemente, muitas questões poderiam aparecer para que houvesse proposições de melhorias para o IFSUL GO. 


\section{ETAPA 5: SELECIONAR}

O propósito de Ambrose e Harris (2011) na etapa Selecionar é extrair dentre alguns testes dos protótipos o que melhor se saiu de acordo com os critérios do time do projeto para preparar o projeto e passar para a Etapa de Implementação.

No caso do IFSUL GO, como apenas um protótipo resultou do processo de design, a ideia foi avaliar como o este seria entregue para os desenvolvedores implementarem de acordo com as especificações apuradas durante o projeto. Este processo é chamado de Design Handoff ou também Entregáveis de Design.

Segundo, Joey Banks (2021) para o Blog do Figma, caso eu estivesse trabalhando diretamente com um time de desenvolvedores, para entregar o projeto para implementação, seria interessante atentar-se aos seguintes itens:

- Compartilhar o arquivo com os desenvolvedores;

- Organizar os arquivos;

- Utilizar componentes;

- Criar Estilos de Cores e de Texto.

Ao tratar desses aspectos de design no IFSUL GO, pode-se afirmar que programadores poderiam ter seu fluxo de trabalho facilitado, ficando mais livres para pensar em questões técnicas de desenvolvimento do software em si. Além disso, o Figma, assim como alguns outros softwares de design de interfaces, como o Adobe XD, oferece ainda uma ferramenta chamada Inspect, que fornece ao desenvolvedor informações na forma de código de como implementar determinado elemento tanto para desenvolvimento web, quanto para mobile incluindo iOS e Android.

Na Figura 14 pode ser visto, no painel à direita, o código para a implementação do componente selecionado no iOS: 


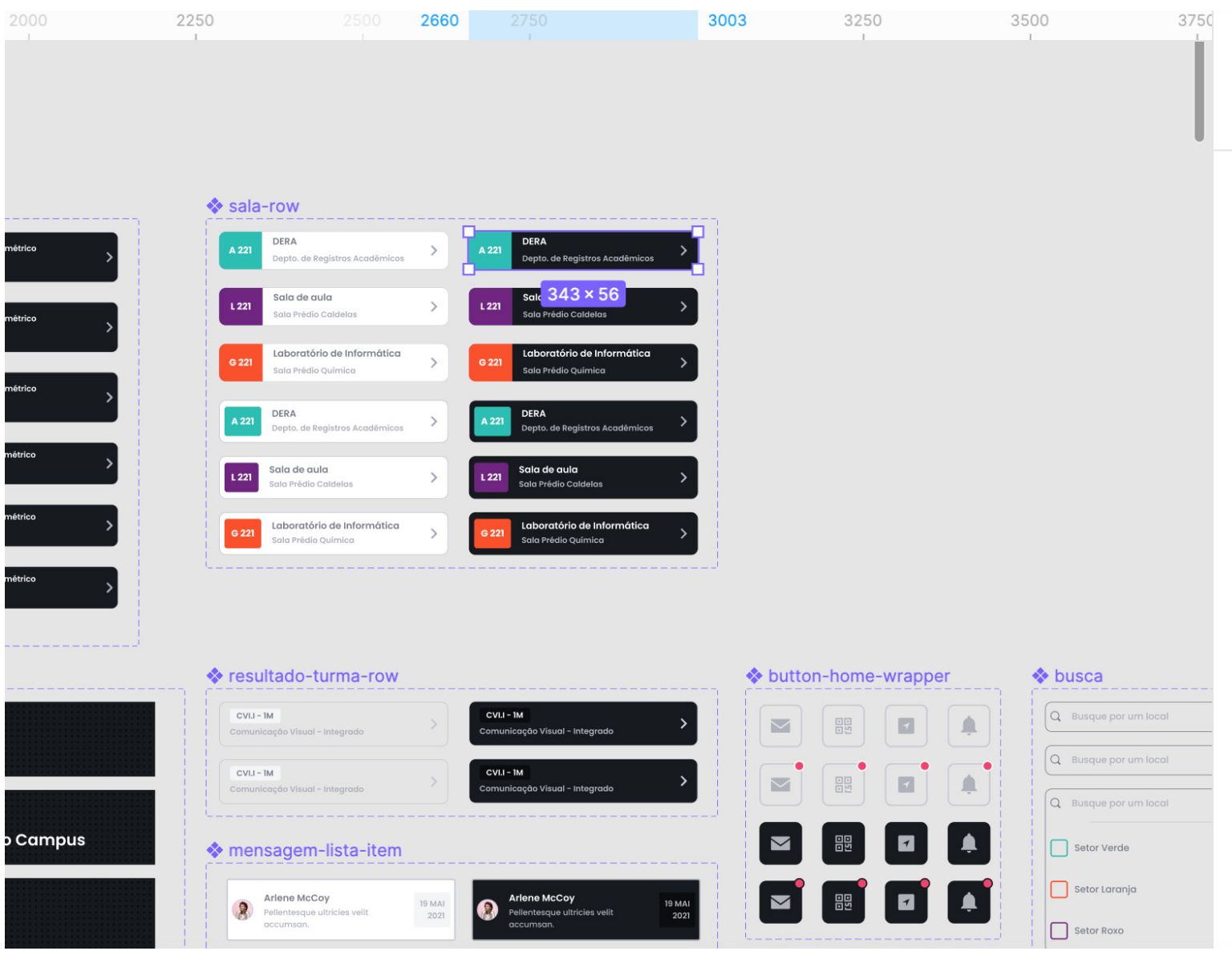

Borders
$\equiv \quad \begin{array}{ll}0.5 \mathrm{px} & \text { Outer border } \\ \text { \#C5C9D4 }\end{array}$

Code

iOS

\langle\rangle$\equiv$

// sala-row

var view $=$ UILabel ()

view.frame $=\operatorname{cGRect}(\mathbf{x}: 0, \mathbf{y}: 0$, width: 343 , height: 56)

view. backgroundColor $=$. white

view. layer . backgroundColor $=$

UIColor(red: 0.09, green:

0.102 , blue: 0.122 , alpha:

1). cgColor

view. layer . cornerRadius $=10$

var stroke $=$ UIView ()

stroke. bounds =

view.bounds.inset $B y(d x:-0.5$, dy: -0.5$)$

stroke. center $=$ view .center

view.addSubview(stroke)

stroke. layer . cornerRadius $=$

10.5

view. bounds $=$

view. bounds. insetBy $(\mathrm{dx}$ dy: -0.5$)$

Figura 14 - Componentes para implementação. Fonte: do autor.

Ainda que a ferramenta forneça todos esses recursos, a etapa seguinte de Implementação, como citado anteriormente, não foi abordada neste projeto por se tratar de uma fase que sairia do escopo do trabalho, em conformidade com Ambrose e Harris (2011), é função do designer estar presente para garantir que as expectativas do projeto sejam alcançadas.

\section{CONSIDERAÇÕES FINAIS}

Os resultados alcançados com essa pesquisa foram satisfatórios para o autor, uma vez que foi atingido o objetivo, considerando que a pesquisa serviu de base para a produção da prática apresentada, de desenvolver um protótipo do aplicativo IFSUL GO utilizando a metodologia de Design Thinking, com auxílio de ferramentas do framework da experiência de usuário de Garrett. 
Ainda que houvesse o conhecimento da importância de métodos aplicados em um projeto de design, até o início deste trabalho, tinham sido utilizados em menor escala pelo autor, muitas vezes com dificuldade em sistematizar processos criativos. No entanto, a estrutura das metodologias aplicadas e a necessidade de documentá-las auxiliaram no crescimento do autor como designer, uma vez que me comprovaram de forma pragmática que num projeto de design o processo é tão essencial quanto o resultado.

O produto originado deste trabalho, foi positivo no sentindo de contribuir para a comunidade, uma vez que tem potencial de ser implementado e impactar na forma com que milhares de pessoas lidam com a localização nas dependências do Câmpus Pelotas do IFSUL, especialmente aquelas que estão tendo um primeiro contato com a instituição. Além disso, espera-se que a exposição dos resultados contribua com futuras pesquisas que tenham o objetivo de melhorar e facilitar a vida em sociedade, entendendo a importância do Design Experiência do Usuário, em um mundo cada vez mais digital.

\section{REFERÊNCIAS BIBLIOGRÁFICAS}

AMBROSE, G.; HARRIS, P. Design Thinking.

São Paulo: Bookman, 2011.

BANKS, J. Guide to Developer Handoff. Disponível em: <https://www.figma.com/best-practices/guideto-developer-handoff/> Acesso em: 20 Jul. 2021.

BORDINI, A., LEITZKE, N., RIBEIRO, C. Relatórios

do Projeto do Sistema de Sinalização do

IFSUL - Câmpus Pelotas. 2021, no prelo. 
BRAUM, M. Como medir a usabilidade de produtos

com System Usability Scale. Design Collective, 2019.

Disponível em: <https://brasil.uxdesign.cc/guia-como-

medir-a-usabilidade-de-produtos-com-system-usability-

scale-sus-e08f4361d9db>. Acesso em: 20 Jul. 2021.

BROWN, T. Design by Change, Revised and

Update. Nova York: Harper Collins, 2019.

GARRETT, J. The Elements of User Experience:

User-Centered Design for the Web and

Beyond. Berkeley-CA: New Riders, 2010. =

IFSUL - CAMPUS PELOTAS. O Câmpus Pelotas.

IFSUL - CAMPUS PELOTAS, 2021. Disponível

em: <http://pelotas.ifsul.edu.br/institucional/o-

campus-pelotas>. Acesso em: 28 Jun. 2021.

MOURA, K. Engenharia Reversa. Engenharia 360,

2021. Disponível em: <https://engenharia360.com/

engenharia-reversa/>. Acesso em: 28 Jun. 2021.

O'GRADY, J.; O'GRADY, K. The Information Design

Handbook. Cincinnati-OH: How Books, 2008.

PC MAGAZINE. Encyclopedia. Disponível

em: < https://www.pcmag.com/encyclopedia/

term/state> Acesso em 19 Jul. 2021.

TEIXEIRA, F. Introdução e Boas Práticas em UX

Design. São Paulo: Casa do Código, 2014.

ROGERS, Y.; SHARP, H.; PREECE, J. Design

de Interação. Hoboken: Wiley, 2013.

USABILITY. System Usability Scale. Disponível em:

<https://www.usability.gov/how-to-and-tools/methods/

system-usability-scale.html> Acesso em: 20 Jul. 2021. 